\title{
Makalah Seminar Tugas Akhir IMPLEMENTASI SISTEM INFORMASI GEOGRAFIS DAERAH PARIWISATA KOTA SEMARANG BERBASIS ANDROID DENGAN GLOBAL POSITIONING SYSTEM (GPS)
}

\author{
Richard R F S ${ }^{1)}$, Kodrat Imam Satoto ${ }^{2)}$, Kurniawan Teguh Martono ${ }^{2)}$ \\ Program Studi Sistem Komputer, Fakultas Teknik, Universitas Diponegoro \\ Jln. Prof. Sudharto, Tembalang, Semarang, Indonesia \\ richard_siahaan@yahoo.com
}

\begin{abstract}
Abstrak-Pariwisata merupakan aspek yang berharga bagi suatu daerah, dengan adanya daerah wisata maka dapat memajukan kesejahteraan masyarakat sekitar. Kota Semarang memiliki daerah pariwisata yang sangat banyak, apabila sarana dan prasarana yang ada dikembangkan lebih lanjut maka dipastikan peningkatan parwisata di Kota Semarang akan semakin bertambah. Penggunaan Teknologi Informasi dapat memajukan daerah pariwisata, sehingga daerah pariwisata dapat dikenal oleh wisatawan yang ingin berkunjung ke Semarang.

Sistem Informasi Geografis yang dibangun menggunakan platform android. Pada Tugas Akhir ini menggunakan Java sebagai bahasa pemorgraman dengan eclipse sebagai perangkat lunak pengembangan. Penggunaan Google Map API sebagai fungsi utama peta dalam menjalankan aplikasi serta PHP sebagai bahasa pemorgaraman sisi server dan MySQL dalam penggunaan basis data.

Hasil dari perancangan Aplikasi Sistem Infomasi Geografis Kota Semarang berbasis Android ini nantinya akan memberikan informasi dalam bentuk peta yang dapat digunakan sebagai referensi bagi wisatawan yang berkunjung. Penggunaan Global Positioning System (GPS) dalam aplikasi ini menjadi hal yang sangat penting dalam menentukan keberadaan wisatawan. Selain itu terdapat rute untuk menuju objek wisata yang dipilih, dalam aplikasi ini juga tersedia fasilitas-fasilitas umum seperti ATM dan Bank, Bandara, Mesjid, Gereja, Rumah Sakit dan lainnya.
\end{abstract}

Kata Kunci : Android, Eclipse, Google Map API, Google Palces API, Android Development Tools, Java.

\section{PENDAHULUAN}

\subsection{Latar Belakang}

Menurut Yoeti (2006) pariwisata merupakan suatu perjalanan yang dilakukan secara perorangan maupun kelompok dari satu tempat ke tempat lain yang sifatnya sementara dan bertujuan untuk mendapatkan kesenangan, dimana di tempat yang dikunjungi tersebut mereka tidak mendapatkan penghasilan dan justru sebagai konsumen.

Namun, kendalanya adalah kurangnya informasi mengenai letak tempat wisata yang ingin dituju. Sehingga diperlukan sebuat Sistem Informasi Geografis yang dapat mendukung kegiatan para wisatawan di kota Semarang. Keberadaan daerah Pariwisata yang ada di kota Semarang merupakan hal yang sangat penting saat ini. Dengan adanya Sistem Informasi Geografis maka informasiinformasi daerah wisata dapat diandalkan.

Sistem informasi Pariwisata kota Semarang yang ada saat ini yaitu berbasis web dimana sistem tersebut memiliki kekurangan yaitu sistem informasi tersebut hanya cocok diakses melalui desktop. Dalam hal ini wisatawan tidak dapat mengetahui keberadaan tempat wisata tanpa menggunakan desktop ketika berada diperjalanan. Keadaan inilah yang coba dimanfaatkan untuk mempermudah wisatawan untuk mengetahui keberaadaan tempat pariwisata menggunakan teknologi mobile ${ }^{[11]}$.

Dalam perkembangannya penggunaan peta Google Map versi dua belum maksimal, kebanyakan menggunakan Google Map versi satu dalam pembuatan peta. Sehingga peta yang ada masih memiliki kekurangan pada tampilan peta $^{[12]}$.

Sistem Informasi Geografis berbasis Android dapat menjadi salah satu alat bantu utama yang mobile interaktif. Karena dengan adanya Sistem Informasi Geografis akan dipetakan letak lokasi pariwisata pada kondisi sesungguhnya 
dalam hal ini peta dari perangkat seluler yang dibawa oleh wisatawan.

\subsection{Tujuan}

Tujuan yang ingin dicapai dari Tugas Akhir ini adalah

1. Membuat perangkat lunak sistem informasi geografis pariwisata berbasis mobile device pada daerah Kota Semarang.

2. Mengimplementasikan Aplikasi Geographic Information System (GIS) pada perangkat bergerak Android

\subsection{Pembatasan Masalah}

Batasan Masalah pada Tugas Akhir ini dibuat agar tidak meluas maka perlu dibuat batasan masalah :

1. Pembuatan sistem informasi geografis ini menggunakan bahasa pemrograman java disertai dengan teknologi Google APIs.

2. Peta dasar yang digunakan dalam sistem informasi geografis ini adalah Google Maps.

3. Tidak membahas tentang teknik pembuatan peta yang digunakan pada aplikasi ini, serta tidak diuji ketepatan koordinat peta kota Semarang.

4. Tidak membahas mengenai penggunaan algoritma dalam menghitung jarak terpendek pada penentuan rute.

5. Lingkup kerja sistem adalah perangkat mobile yang menggunakan sistem operasi Android.

\section{DASAR TEORI}

Menurut Yoeti (2006) pariwisata merupakan suatu perjalanan yang dilakukan secara perorangan maupun kelompok dari satu tempat ke tempat lain yang sifatnya sementara dan bertujuan untuk mendapatkan kesenangan, dimana di tempat yang dikunjungi tersebut mereka tidak mendapatkan penghasilan dan justru sebagai konsumen.
Manusia membutuhkan sesuatu yang dapat membuat hidupnya lebih seimbang dan berwarna, dengan melakukan perjalanan ke suatu tempat baru dengan berbagai macam kegiatan yang bermakna dan disukai. Pariwisata dalam perkembangan seni budaya dan ekonomi juga memiliki peran yang besar, karena dengan adanya orang atau sekelompok orang yang berkunjung di suatu daerah tujuannya adalah mencari tahu sesuatu ciri khas atau keunikan daerah tersebut. Sehingga daerah tersebut dapat mengembangkan atau memunculkan, makanan, kerajinan, ataupun kebudayaan yang dimiliki.

Para wisatawan akan kesulitan jika datang di suatu daerah yang baru tanpa mengetahui alamat dan tujuan wisatanya, lagipula saat berwisata pasti memerlukan tempat menginap, tempat makan, dan tempat ibadah di daerah tersebut, sehingga banyak informasi yang diperlukan ${ }^{[11]}$.

Sistem yang akan dibangun ini adalah sebuah aplikasi android yang dijalankan oleh pengguna dengan menggunakan perangkat mobile yang mendukung sistem operasi Android

Pengguna berkomunikasi dengan sistem melalui aplikasi yang sudah ada dipasang di perangkat mobile. Aplikasi mobile inilah yang akan memberikan informasi yang diperlukan oleh pengguna, apabila pengguna melakukan interaksi pada aplikasi maka aplikasi akan mengirimkan data ke server sistem GPS yang ada kemudian akan meminta gambaran peta melalui server Google Map. Hasilnya adalah berupa lokasi posisi pengguna, gambar peta, serta objek-objek yang dimilki oleh peta Google Map yang selanjutnya akan di kembalikan ke perangkat pengguna berupa tampilan peta yang memiliki point-point lokasi yang diminta didalamnya. 


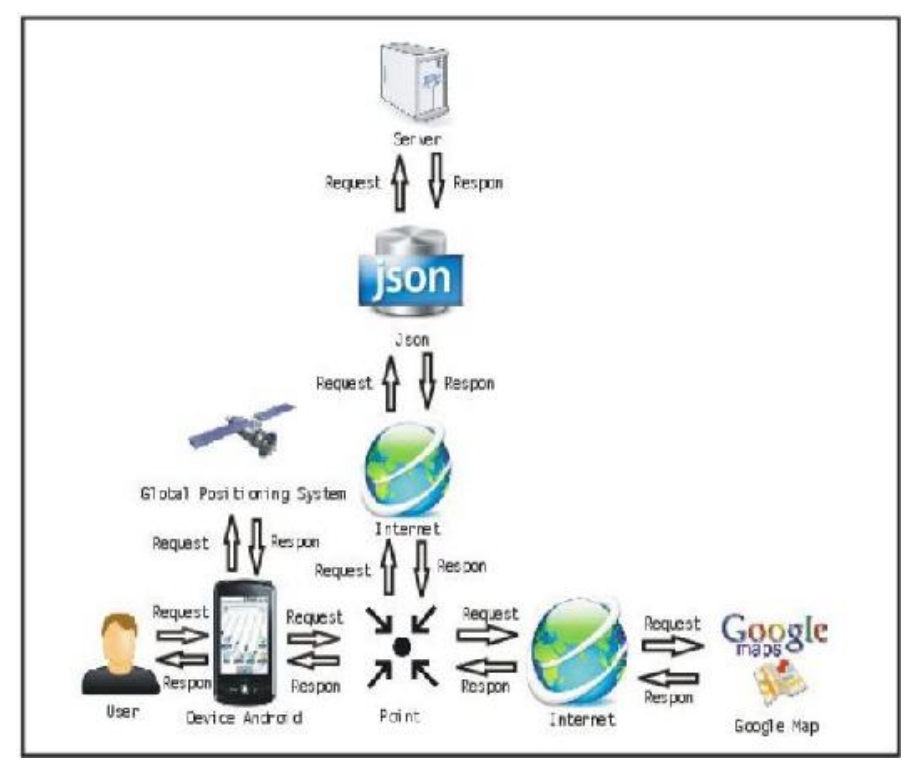

Gambar 2.3 Arsitektur Sistem ${ }^{[12]}$

\subsection{Sistem Informasi Geografis}

Sistem Informasi Geografis menurut Charter Denny (2004), merupakan sistem yang dirancang untuk bekerja dengan data yang tereferensi secara spasial atau koordinat-koordinat geografi. SIG memiliki kemampuan untuk melakukan pengolahan data dan melakukan operasi-operasi tertentu dengan menampilkan dan menganalisa data.

Aplikasi SIG saat ini tumbuh tidak hanya secara jumlah aplikasi namun juga bertambah dari jenis keragaman aplikasinya. Pengembangan aplikasi SIG kedepannya mengarah kepada aplikasi berbasis andorid yang lebih dikenal dengan nama mobile SIG.

Hal ini disebabkan karena pengembangan aplikasi di lingkungan jaringan telah menunjukan potensi yang besar dalam kaitannya dengan geo informasi. Sebagai contoh adalah adanya peta online sebuah kota dimana pengguna dapat dengan mudah mencari lokasi yang diinginkan secara online melalui jaringan internet tanpa mengenal batas geografi penggunanya.

\subsection{Google Map API}

API atau Application Programming Interface merupakan suatu dokumentasi yang terdiri dari interface, fungsi, kelas, struktur dan sebagainya untuk membangunsebuah perangkat lunak. Dengan adanya API ini, maka memudahkan programmer untuk "membongkar" suatu software untuk kemudian dapat dikembangkan atau diintegrasikan dengan perangkat lunak yang lain. API dapat dikatakan sebagai penghubung suatu aplikasi dengan aplikasi lainnya yang memungkinkan programmer menggunakan system function. Proses ini dikelola melalui operating system. Keunggulan dari API ini adalah memungkinkan suatu aplikasi dengan aplikasi lainnya dapat saling berhubungan dan berinteraksi. Bahasa yang digunakan oleh Google Map yang terdiri dari HTML, JavaScript dan AJAX serta XML, memungkinkan untuk menampilkan peta Google Map di website lain.

Google juga menyediakan layanan Google Map API yang memungkinkan para pengembang untuk mengintegrasikan Google Map ke dalam website masing-masing dengan menambahkan data point sendiri. Dengan menggunakan Google Map API, Google Map dapat ditampilkan pada web site eksternal. Agar aplikasi Google Map dapat muncul di website tertentu, diperlukan adanya API key. API key merupakan kode unik yang digenerasikan oleh Google untuk suatu website tertentu, agar server Google Map dapat mengenali ${ }^{[9]}$. 


\section{Perancangan Sistem}

Sistem adalah sekumpulan komponen yang saling berhubungan dan bekerjasama untuk mencapai suatu tujuan. Perancangan sistem berhubungan dengan bagaimana fungsionalitas sistem disediakan oleh komponen-komponen sistem. Perancangan program Sistem Informasi Geografis Daerah Pariwisata Kota Semarang Berbasis Android Dengan Global Positioning System akan disusun berdasarkan analisis kebutuhan dan perancangan yang terstruktur sehingga tercapai tujuan dari pembuatan aplikasi.

\subsection{Tahapan Pengembangan Sistem Informasi Geografis}

1. Menentukan tujuan dan masalah

Definisi permasalahan dan tujuan yang menjadi landasan untuk penelitian yang tepat dan jelas.

2. Penelitian dan persiapan

Perancang harus mempelajari topik yang sudah dipilih dan melakukan penelitian. Perancang harus mengumpulkan pengetahuan dan wawasan yang mendukung topik dari rancangan permainan yang akan dibuat.

3. Perancangan

Perancangan bertujuan untuk membuat sistem dan perancangan antarmuka dari sistem dan program.

4. Pemrograman

Pemrograman merupakan tahap mengimplementasikan hasil perancangan ke dalam bentuk pengkodean sehingga aplikasi dapat dibangun.

5. Pengujian

Pengujian bertujuan untuk mengumpulkkan informasi dari aplikasi, informasi tersebut dapat digunakan untuk memperbaiki kesalahan dan menyempurnakan aplikasi. Ada dua bentuk cara pengujian yaitu pengembang sendiri yang melakukan pengujian dan pengguna yang melakukan pengujian

\subsection{Perancangan Sistem Perangkat Lunak dengan Menggunakan Metode Waterfall \\ 3.2.1 Analisis Kebutuhan}

Permasalahan merupakan latar belakang untuk membangun sebuah sistem yang baru, seringkali perekayasa perangkat lunak kesulitan dalam menentukan apa saja yang harus dilakukan oleh sistem. Deskripsi layanan dan batasan merupakan kebutuhan bagi sistem dan proses menemukan, menganalisis, mendokumentasikan dan memeriksa layanan dan batasan ini disebut analisis kebutuhan. Analisis kebutuhan ini diperlukan agar sistem dapat mencapai tujuan yang diharapkan.

\subsubsection{Deskripsi umum}

Aplikasi yang akan dibuat merupakan sebuah sistem informasi geografis pada perangkat bergerak berbasis android, pengguna dapat mengetahui keberadaan tempat wisata yang ada di kota Semarang. Aplikasi ini dibuat dengan perangkat pengembangan Eclipse dan bahasa Java

\subsubsection{Kebutuhan Fungsional}

Kebutuhan fungsional merupakan fungsionalitas atau layanan yang harus diberikan oleh sistem. Kebutuhan ini akan bergantung pada jenis perangkat lunak yang sedang dikembangkan, pengguna yang diharapkan menggunakan perangkat lunak tersebut dan jenis sistem yang akan digunakan. Kebutuhan fungsional dari aplikasi ini adalah:

a. Adanya fasilitas untuk mencari lokasi saat ini dengan koordinat GPS pada perangkat. Sehingga memudahkan pengguna untuk mengetahui keberadaan posisi dari pengguna. Dalam menu posisi terdapat juga informasi mengenai keadaan cuaca kota Semarang.

b. Adanya fasilitas daftar pariwisata yang terstruktur sehingga pengguna dapat mengetahui objek-objek wisata apa saja yang ada di Kota 
Semarang, dalam fasilitas tersebut juga terdapat galeri gambar, dimana pengguna dapat melihat gambargambar mengenai objek wisata tersebut. Adanya fasilitas info lengkap untuk pengunjung mengetahui deskripsi dan info yang dibutuhkan pada obyek wisata. Setelah pengunjung mengetahui letak lokasi wisata yang di inginkan, pengunjung juga dapat melihat informasi atau deskripsi obyek wisata tersebut.

c. Adanya fasilitas rute untuk pengunjung dapat mengetahui rute perjalanan yang harus di lalui untuk sampai ke tempat tujuan. Pengunjung yang belum mengetahui jalan menuju titik lokasi obyek wisata, dapat dipermudah dengan fasilitas rute ini sebagai petunjuk arah.

d. Adanya fasilitas untuk mencari fasilitas-fasilitas tempat umum seperti ATM, Rumah Sakit, Gereja, Mesjid, Bandara, dan lainnya. Dengan adanya fasilitas ini pengguna dapat mengetahui keberadaan fasilitas umum di sekitarnya.

e. Adanya fasilitas untuk mengetahui event atau festival yang sedang berlangsung saat ini di kota Semarang.

\subsubsection{Kebutuhan non-fungsional}

Kebutuhan non-fungsional merupakan kebutuhan yang tidak langsung berhubungan dengan spesifik yang disediakan oleh sistem. Kebutuhan ini berhubungan dengan properti sistem yang muncul belakangan, seperti keandalan, waktu tanggap dan penempatan pada media penyimpanan. Batasan sistem mengenai kemampuan piranti masukan dan keluaran yang dipakai pada antarmuka sistem juga termasuk dalam kebutuhan non-fungsional. Kebutuhan nonfungsional aplikasi ini antara lain:

1. Operasional

Aplikasi ini dapat berjalan sistem operasi minimal Android Gingerbread.

\section{Ukuran}

Ukuran aplikasi dibawah $10 \mathrm{Mb}$.

\subsection{Perancangan dengan Unified Modeling Language \\ 3.3.1 Use Case Diagram}

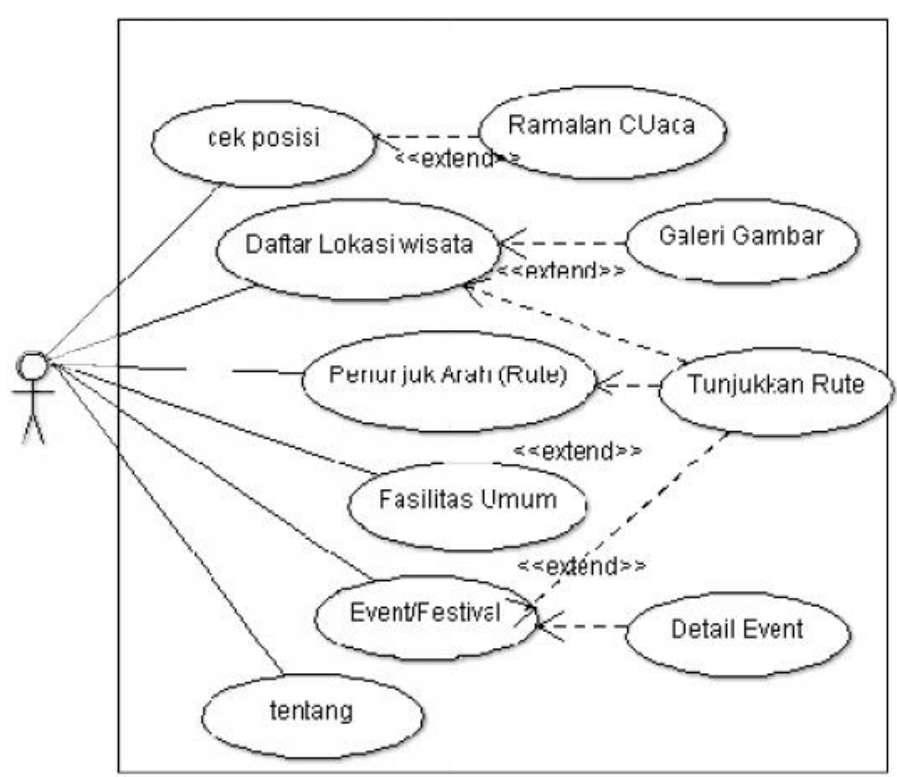

Gambar 3.1 Use Case Diagram 


\subsubsection{Activity Diagram}

\subsubsection{Activity Diagram Posisiku}

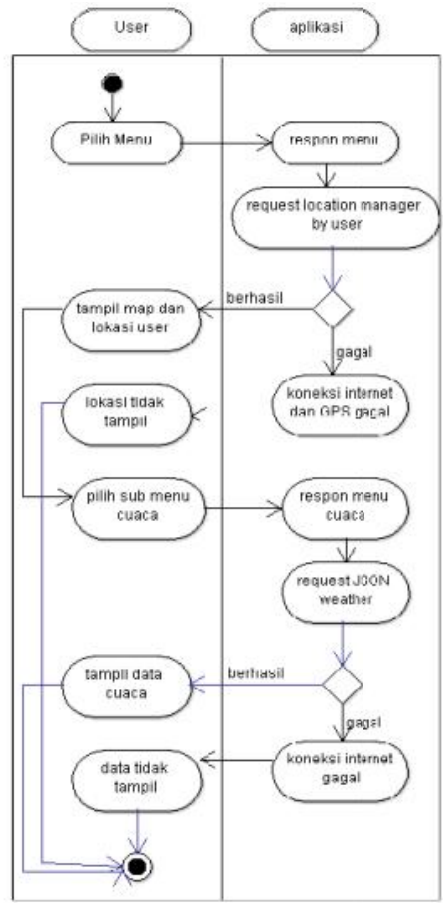

Gambar 3.3 Activity Diagram Posisiku

\subsubsection{Activity Diagram Melihat daftar Wisata}

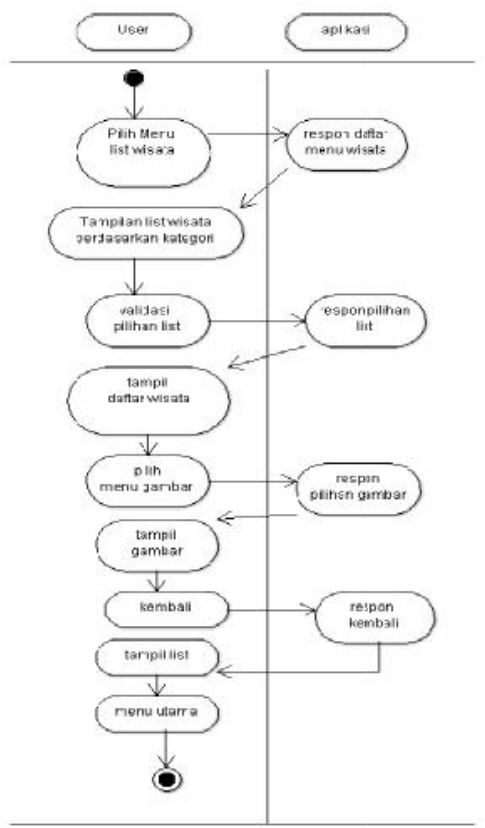

Gambar 3.4 Activity Diagram Lihat

Daftar Wisata

\subsubsection{Activity Diagram Melihat Petunjuk Rute}

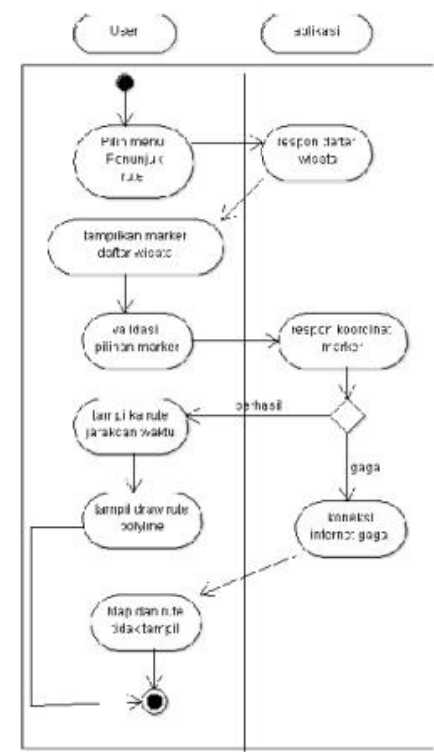

Gambar 3.5 Activity Diagram Penunjuk Rute

\subsubsection{Activity Diagram Melihat Fasilitas Umum}

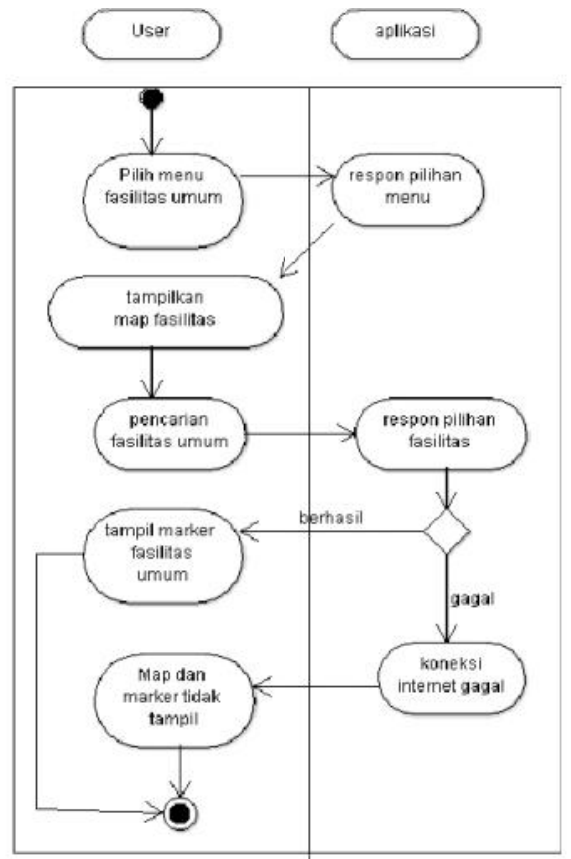

Gambar 3.6 Activity Diagram 
3.3.2.5 Activity Diagram Event/Festival

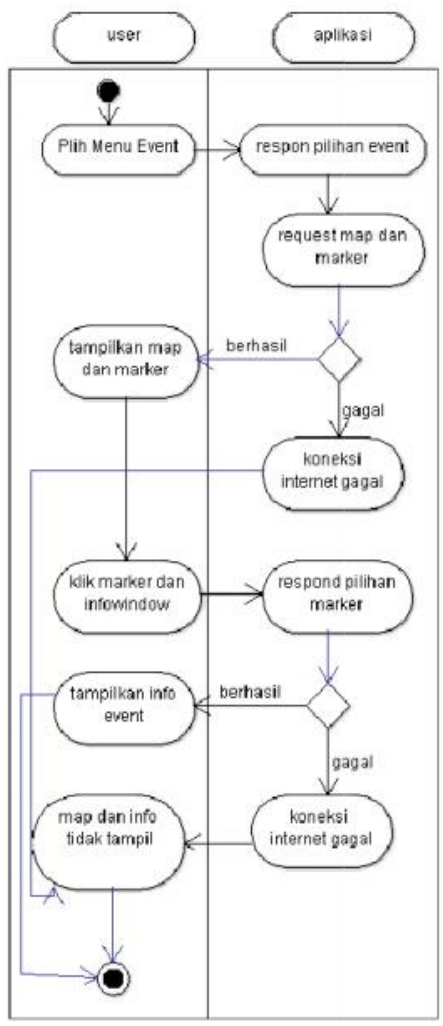

Gambar 3.7 Activity Diagram Event/Festival 3.3.3 Sequence Diagram

3.3.3.1 Sequence Diagram

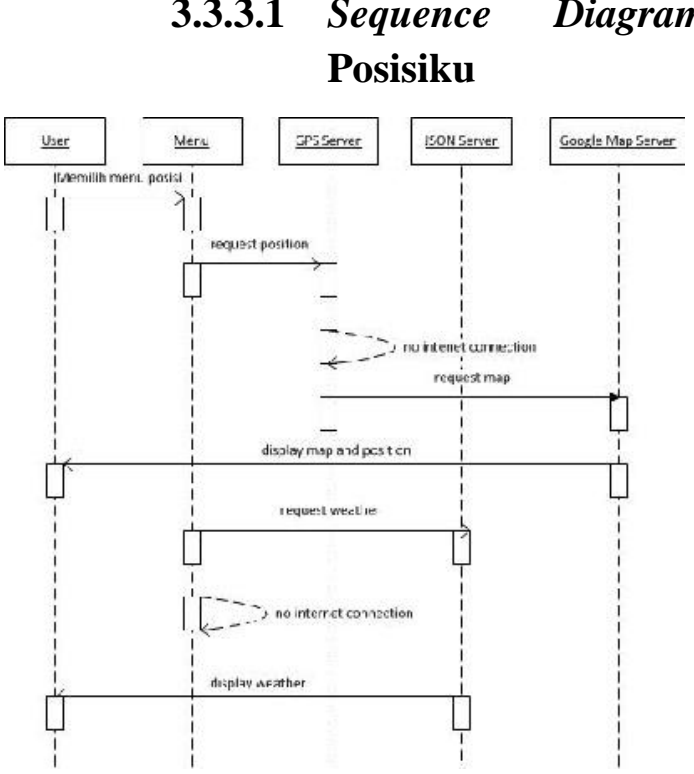

Gambar3.8 Sequence Diagram Posisiku

\subsubsection{Sequence Diagram Daftar Wisata}

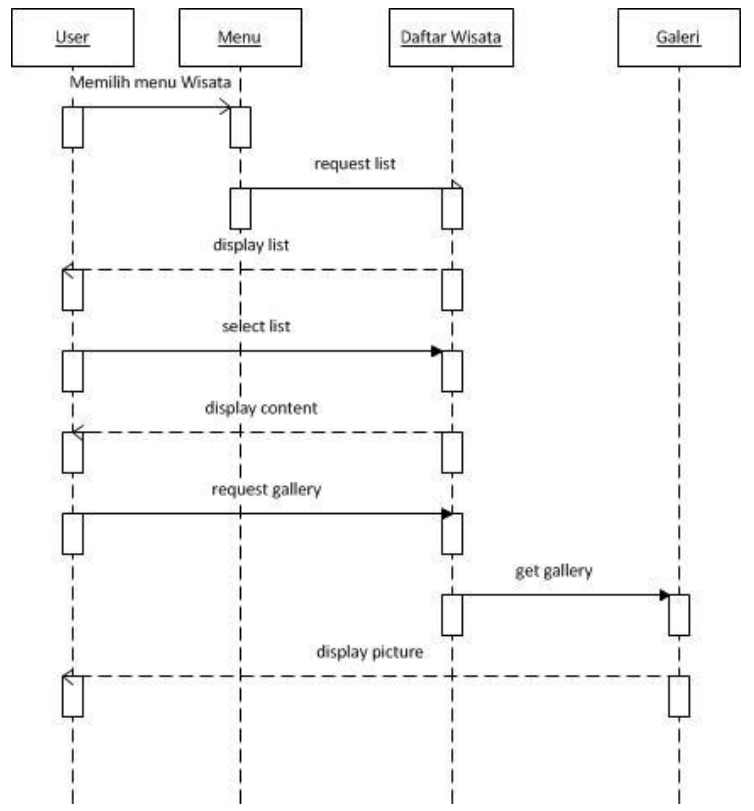

Gambar 3.9 Sequence Diagram Daftar Wisata

\subsubsection{Sequence Diagram Penunjuk Arah}

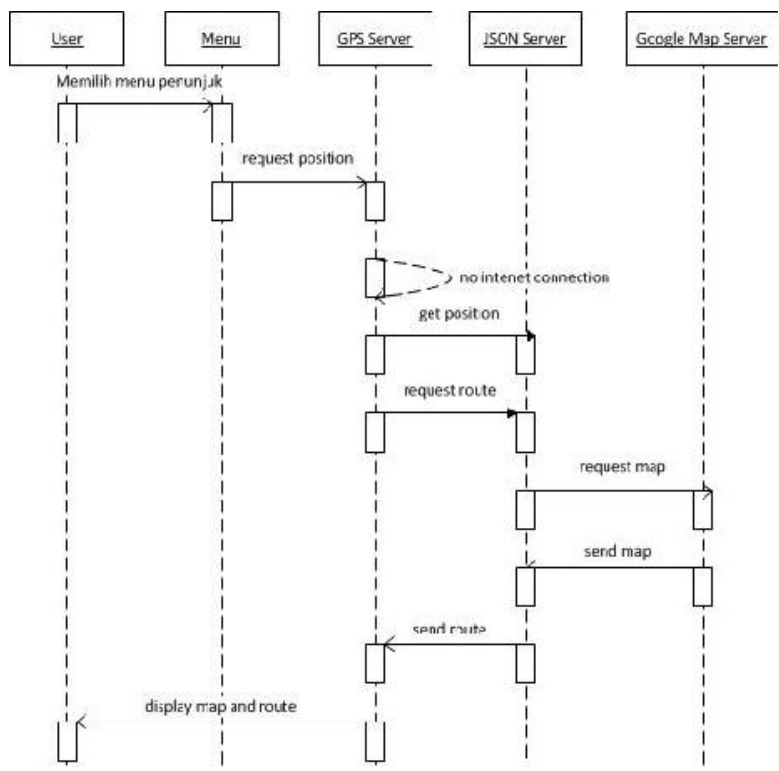

Gambar 3.10 Sequence Diagram Penunjuk Arah (Rute) 


\subsubsection{Sequence Diagram Fasilitas} Umum

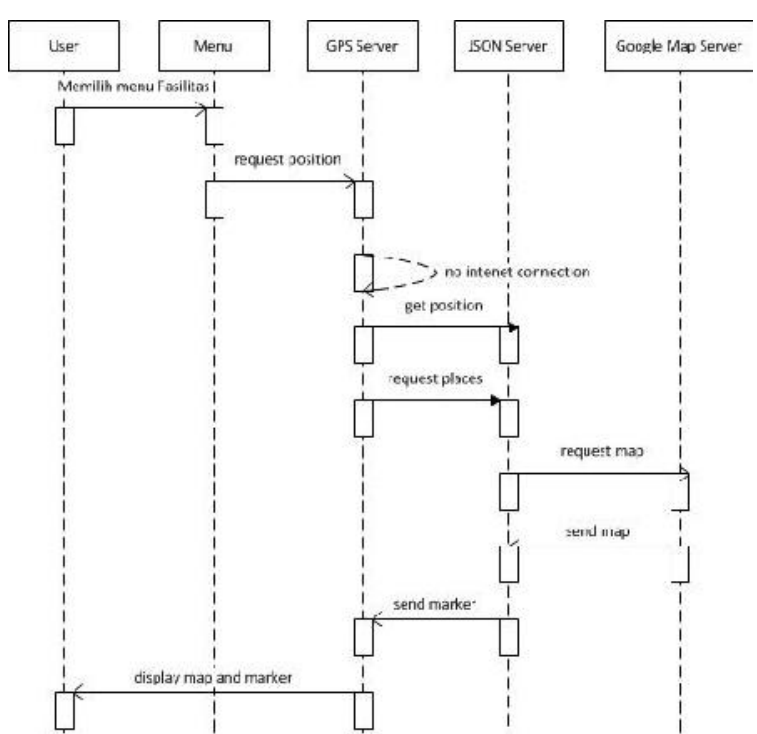

Gambar 3.11 Sequence Diagram Fasilitas

$$
\text { Umum }
$$

\subsubsection{Sequence Diagram Event dan Festival}

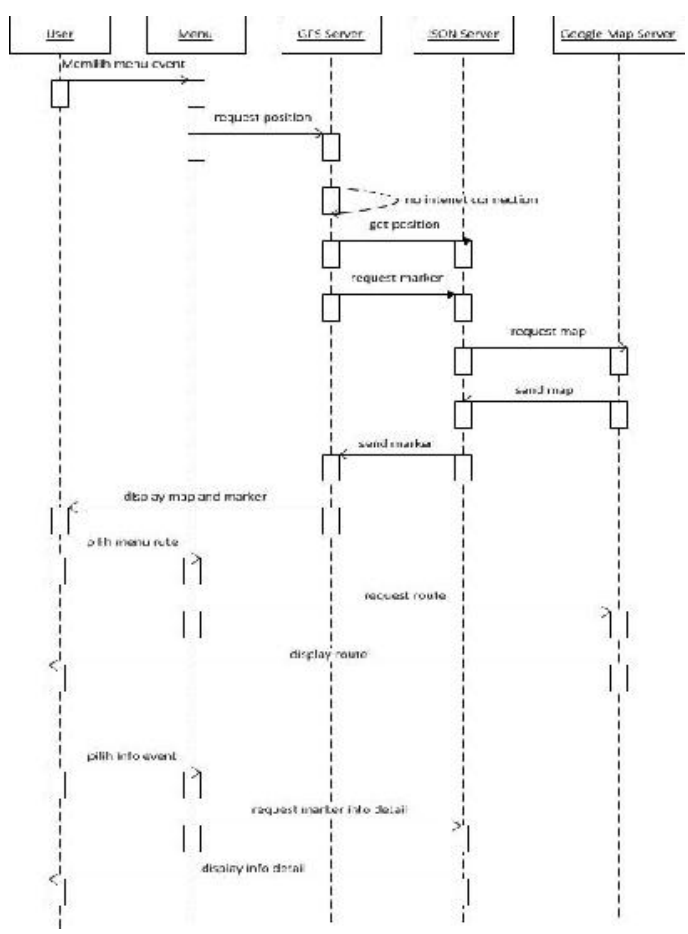

Gambar 3.12 Sequence Diagram Event atau Festival
3.3.4 Class Diagram

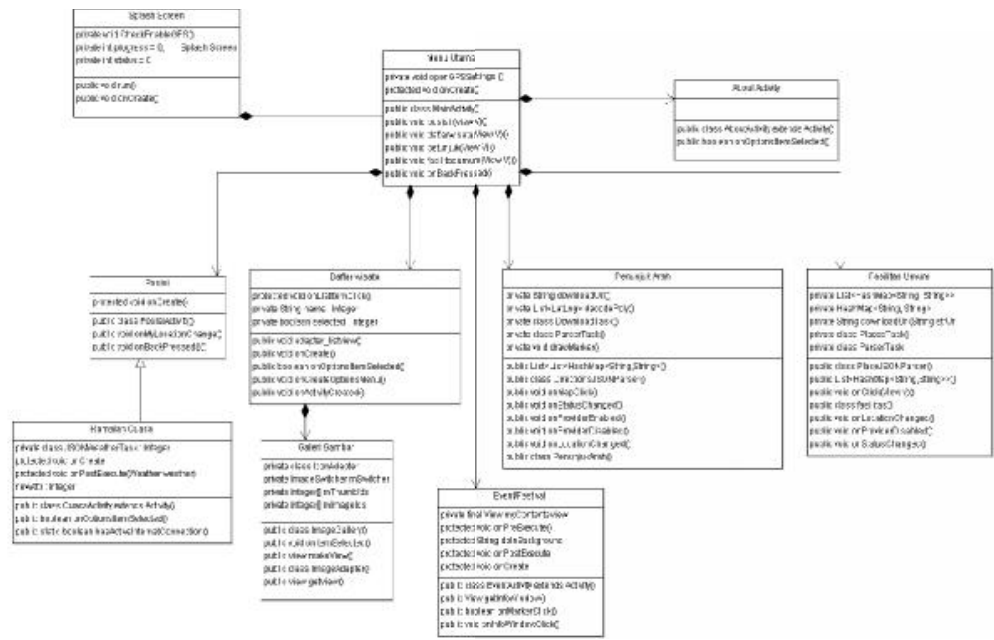

Gambar 3.13 Class Diagram

\subsubsection{Implementasi Antarmuka Sistem Informasi Pariwisata Kota Semarang}

Gambar 4.6 Tampilan splash screen

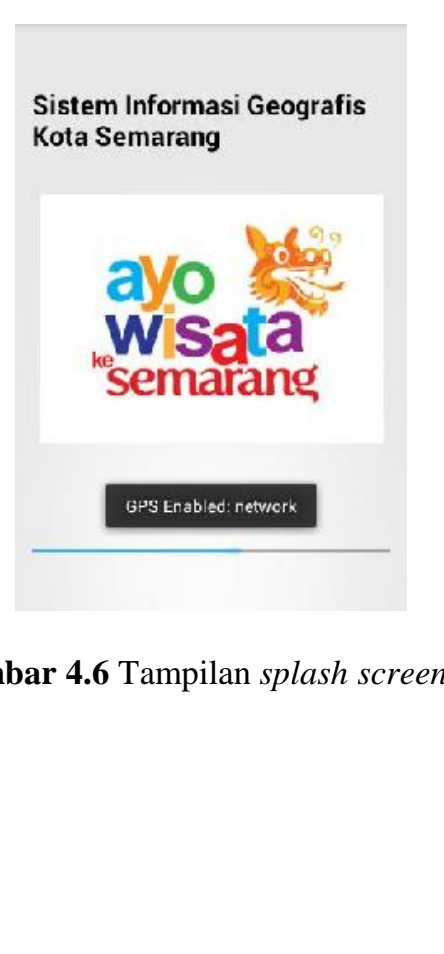




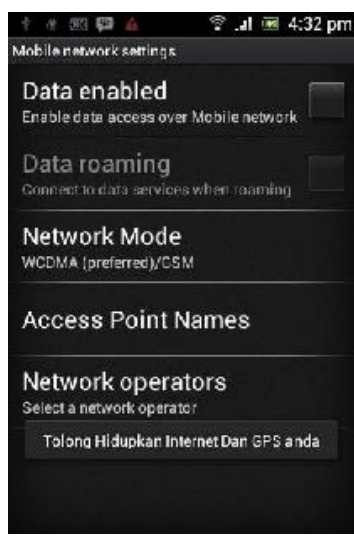

Gambar 4.7 Tampilan Notifikasi GPS dan Internet

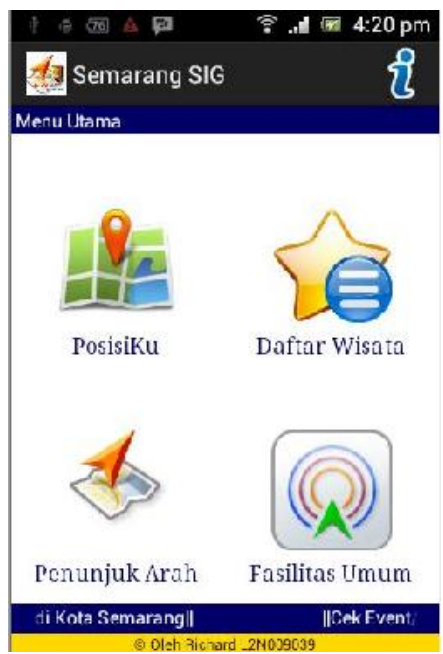

Gambar 4.8 Tampilan Menu Utama

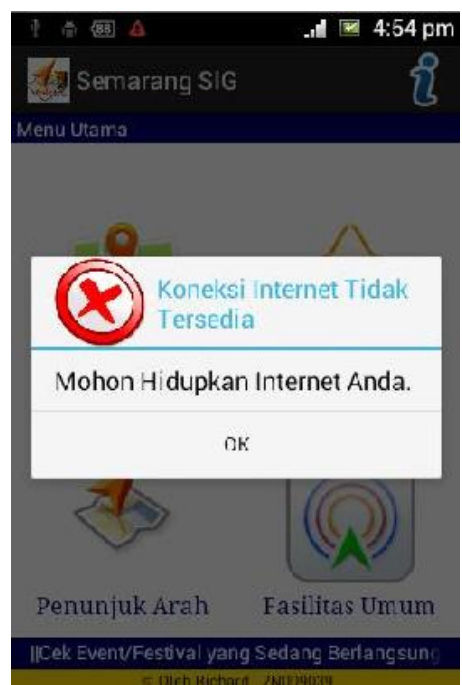

Gambar 4.9 Tampilan Peringatan Koneksi Internet

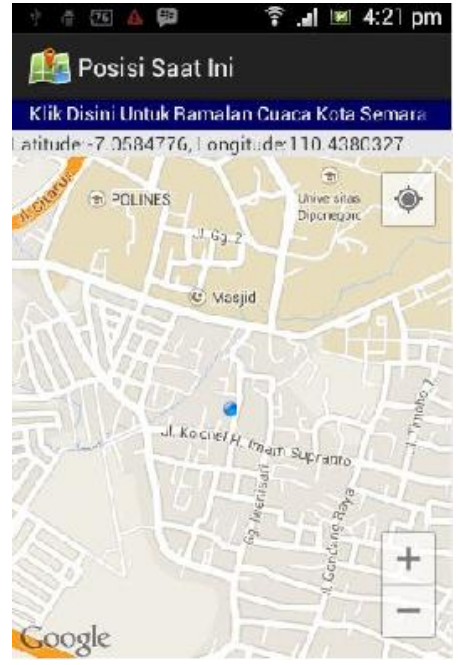

Gambar 4.10 Tampilan Menu Posisi saat ini

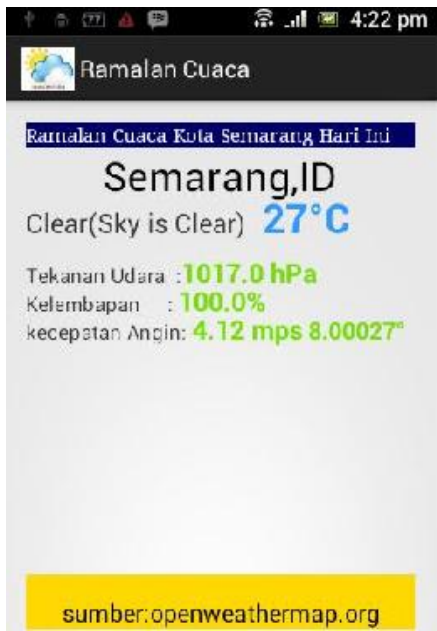

Gambar 4.11 Tampilan Ramalan Cuaca

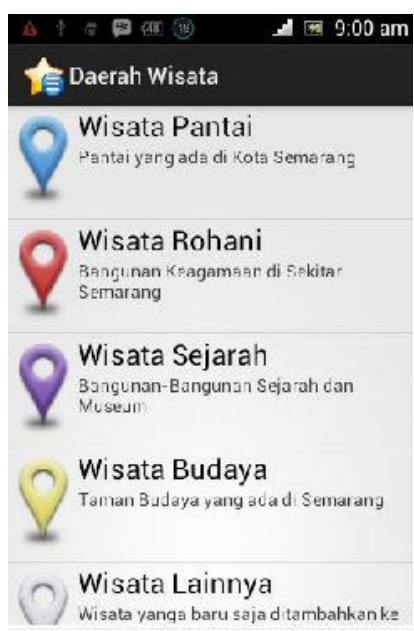

Gambar 4.12 Tampilan Daftar Wisata 

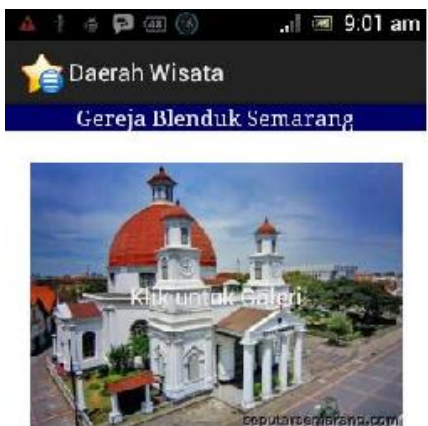

Jl.Letjend Suprapto 32 Semarang

Tunjukkan Rute

L.Husitude -6. 968207 Lati.ude 11C.127518

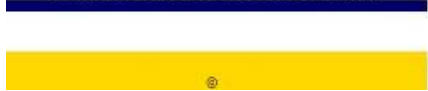

Gambar 4.13 Tampilan Menu daerah wisata

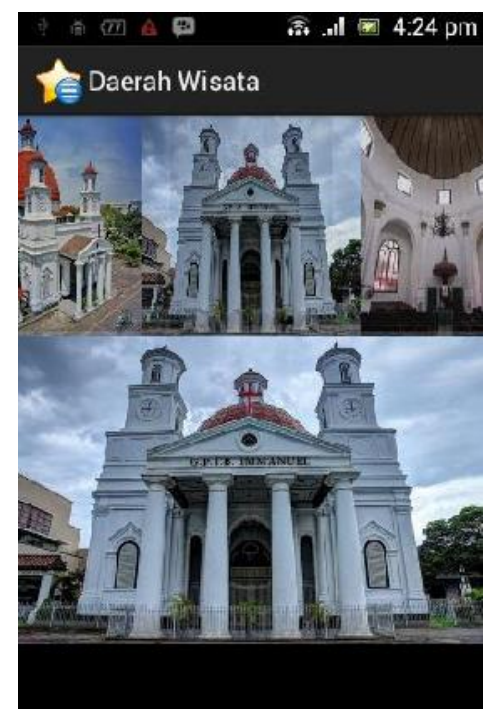

Gambar 4.14 Tampilan Galeri Gambar

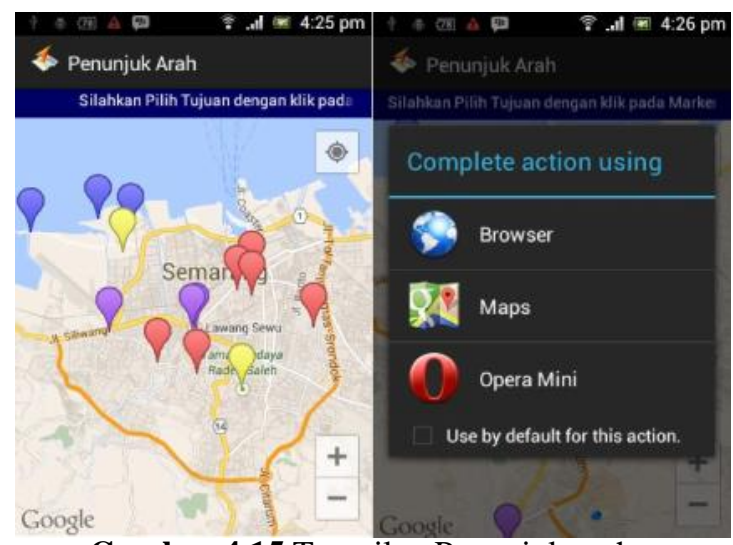

Gambar 4.15 Tampilan Penunjuk arah Daerah Wisata

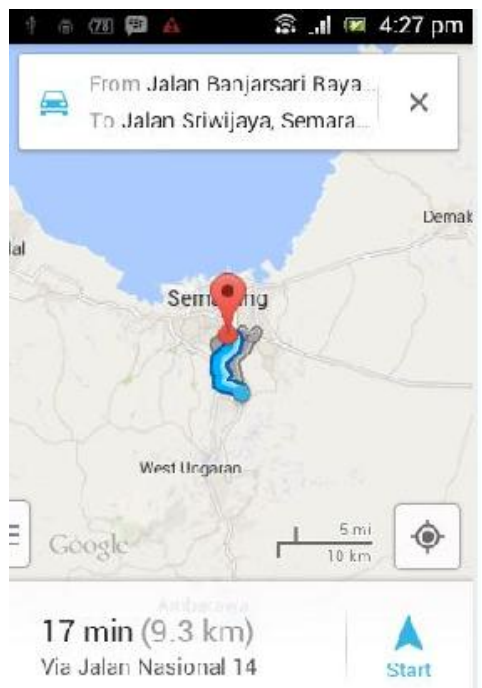

Gambar 4. 16 Tampilan Penunjuk arah

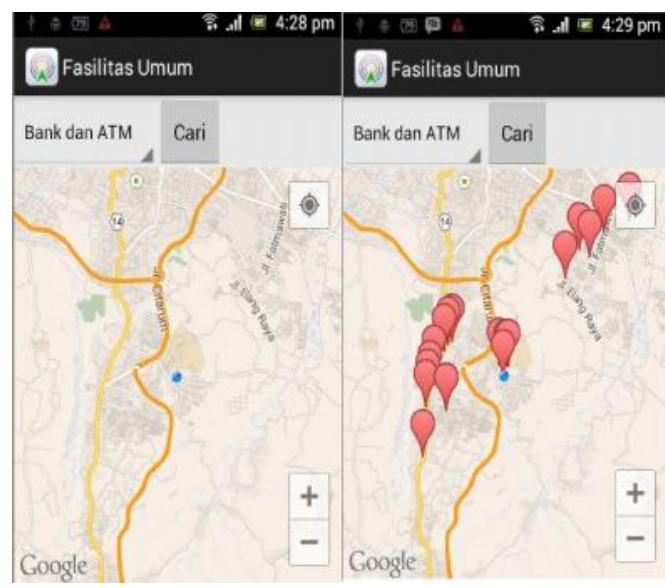

Gambar 4.17 Tampilan menu Fasilitas Umum

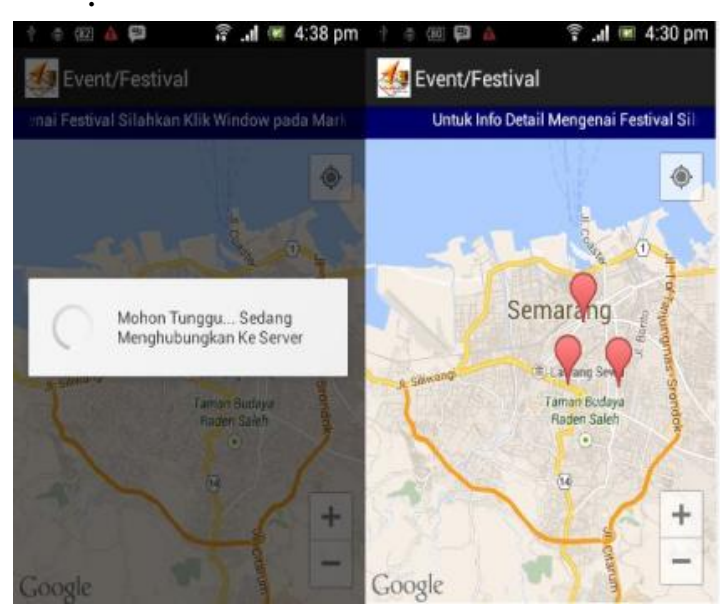

Gambar 4.18 Tampilan menu Event atau Festival 


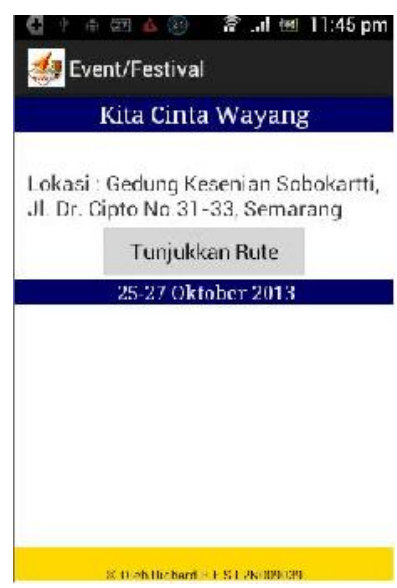

Gambar 4.19 Tampilan deskripsi menu event

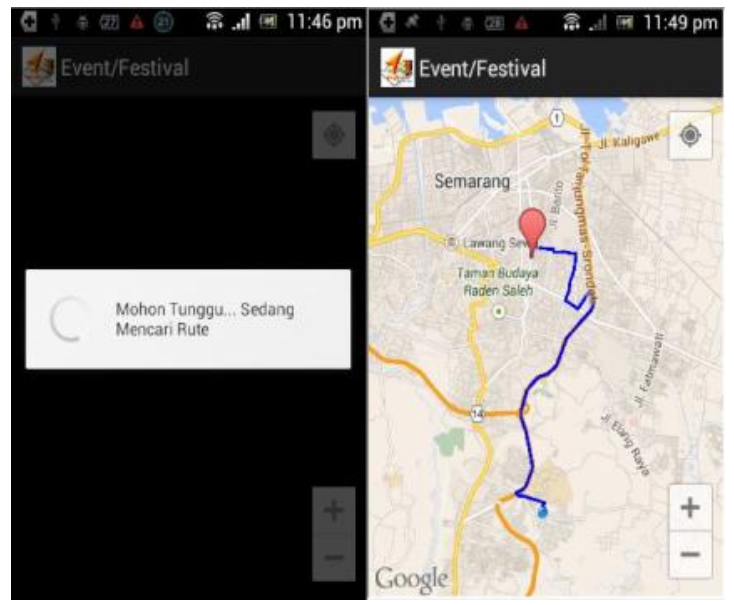

Gambar 4.20 Tampilan Rute Event/Festival

\subsection{Pengujian}

\subsubsection{Pengujian Blackbox}

Tabel 4.1 Pengujian blackbox

\begin{tabular}{|c|c|c|c|}
\hline $\begin{array}{c}\text { Nama } \\
\text { Penguji } \\
\text { an }\end{array}$ & $\begin{array}{c}\text { Bentuk } \\
\text { Pengujia } \\
\text { n }\end{array}$ & $\begin{array}{c}\text { Hasil } \\
\text { Yang } \\
\text { Diharap } \\
\text { kan }\end{array}$ & $\begin{array}{c}\text { Hasil } \\
\text { Penguji } \\
\text { an }\end{array}$ \\
\hline $\begin{array}{c}\text { Pengujian } \\
\text { Koneksi } \\
\text { Internet }\end{array}$ & $\begin{array}{c}\text { Menonaktif } \\
\text { kan } \\
\text { koneksi } \\
\text { internet }\end{array}$ & $\begin{array}{c}\text { Muncul } \\
\text { tampilan } \\
\text { koneksi } \\
\text { internet } \\
\text { tidak } \\
\text { tersedia }\end{array}$ & Berhasil \\
\hline $\begin{array}{c}\text { Pengujian } \\
\text { Menu } \\
\text { Posisiku }\end{array}$ & $\begin{array}{c}\text { Mengklik } \\
\text { menu } \\
\text { Posisiku }\end{array}$ & $\begin{array}{c}\text { Muncul } \\
\text { tampilan } \\
\text { menu } \\
\text { posisiku }\end{array}$ & Berhasil \\
\hline
\end{tabular}

\begin{tabular}{|c|c|c|c|}
\hline $\begin{array}{l}\text { Penguijan } \\
\text { sub menu } \\
\text { ramalam } \\
\text { cuaca }\end{array}$ & $\begin{array}{l}\text { Mengklik } \\
\text { menu } \\
\text { ramalan } \\
\text { cuaca }\end{array}$ & $\begin{array}{l}\text { Muncul } \\
\text { ramalan } \\
\text { cuaca }\end{array}$ & Berhasil \\
\hline $\begin{array}{c}\text { Pengujian } \\
\text { Menu } \\
\text { Daftar } \\
\text { wisata }\end{array}$ & $\begin{array}{c}\text { Mengklik } \\
\text { menu } \\
\text { daftar } \\
\text { wisata }\end{array}$ & $\begin{array}{c}\text { Muncul } \\
\text { nama } \\
\text { daerah } \\
\text { wisata dan } \\
\text { deskripsi } \\
\text { wisata }\end{array}$ & Berhasil \\
\hline $\begin{array}{l}\text { Pengujian } \\
\text { Galeri } \\
\text { Gambar }\end{array}$ & $\begin{array}{l}\text { Mengklik } \\
\text { menu } \\
\text { galeri } \\
\text { gambar }\end{array}$ & $\begin{array}{l}\text { Muncul } \\
\text { galeri } \\
\text { gambar }\end{array}$ & Berhasil \\
\hline $\begin{array}{l}\text { Pengujian } \\
\text { Menu } \\
\text { penunjuk } \\
\text { arah }\end{array}$ & $\begin{array}{l}\text { Mengklik } \\
\text { menu } \\
\text { penunjuk } \\
\text { arah }\end{array}$ & $\begin{array}{c}\text { Muncul } \\
\text { menu } \\
\text { penunjuk } \\
\text { arah }\end{array}$ & Berhasil \\
\hline $\begin{array}{l}\text { Pengujian } \\
\text { Menu } \\
\text { fasilitas } \\
\text { umum }\end{array}$ & $\begin{array}{l}\text { Mengklik } \\
\text { menu } \\
\text { fasilitas } \\
\text { umum }\end{array}$ & $\begin{array}{l}\text { Muncul } \\
\text { Menu } \\
\text { fasilitas } \\
\text { umum }\end{array}$ & Berhasil \\
\hline $\begin{array}{c}\text { Pengujian } \\
\text { Menu } \\
\text { Event } \\
\text { atau } \\
\text { festival }\end{array}$ & $\begin{array}{l}\text { Mengklik } \\
\text { menu event } \\
\text { atau } \\
\text { festival }\end{array}$ & $\begin{array}{c}\text { Muncul } \\
\text { Menu event } \\
\text { atau } \\
\text { festival }\end{array}$ & Berhasil \\
\hline $\begin{array}{l}\text { Pengujian } \\
\text { Rute }\end{array}$ & $\begin{array}{l}\text { Mengklik } \\
\text { Menu } \\
\text { tunjukkan } \\
\text { rute }\end{array}$ & $\begin{array}{l}\text { Muncul } \\
\text { rute pada } \\
\text { menu event }\end{array}$ & Berhasil \\
\hline $\begin{array}{l}\text { Pengujian } \\
\text { Tombol } \\
\text { Cari } \\
\text { Fasilitas } \\
\text { umum }\end{array}$ & $\begin{array}{c}\text { Mengklik } \\
\text { tombol } \\
\text { Cari }\end{array}$ & $\begin{array}{c}\text { Muncul } \\
\text { fasilitas } \\
\text { umum yang } \\
\text { diinginkan }\end{array}$ & Berhasil \\
\hline
\end{tabular}

\subsubsection{Kuisioner}

Tabel 4.2 Pengujian kuisioner

\begin{tabular}{|c|c|c|c|}
\hline \multirow{2}{*}{ No } & \multirow{2}{*}{ Pertanyaan } & \multicolumn{2}{c|}{ Jawaban } \\
\cline { 3 - 4 } 1. & Ya & Tidak \\
\hline \multicolumn{3}{|c|}{ Pengujian Pre Test } \\
\hline & $\begin{array}{c}\text { Apakah anda } \\
\text { mengetahui lokasi- } \\
\text { lokasi Wisata di } \\
\text { Kota Semarang }\end{array}$ & 2 & 8 \\
& $\begin{array}{c}\text { Apakah anda } \\
\text { mengetahui lokasi } \\
\text { wisata Kelenteng } \\
\text { Sam Poo Kong di } \\
\text { Kota Semarang }\end{array}$ & 3 & 7 \\
\hline & & \\
\hline
\end{tabular}




\begin{tabular}{|c|c|c|c|}
\hline 3. & $\begin{array}{c}\text { Apakah anda } \\
\text { mengetahui rute } \\
\text { menuji lokasi wisata } \\
\text { Kelenteng Sam Poo } \\
\text { kong di kota } \\
\text { Semarang? }\end{array}$ & 3 & 7 \\
\hline 4. & $\begin{array}{c}\text { Apakah anda } \\
\text { mengetahui rute } \\
\text { terpendek menuju } \\
\text { lokasi wisata } \\
\text { Kelenteng Sam Poo } \\
\text { Kong di Kota } \\
\text { Semarang }\end{array}$ & 2 & 8 \\
\hline \multicolumn{4}{|c|}{ Pengujian POST TEST } \\
\hline 5 & $\begin{array}{c}\text { Apakah anda } \\
\text { menjadi mengenal } \\
\text { lokasi-lokasi wisata } \\
\text { di Kota Semarang }\end{array}$ & 8 & 2 \\
\hline 6 & $\begin{array}{c}\text { Apakah anda } \\
\text { menjadi mengetahui } \\
\text { adanya Kelenteng } \\
\text { Sam Poo Kong di } \\
\text { kota Semarang }\end{array}$ & 8 & 2 \\
\hline 7 & $\begin{array}{l}\text { Apakah anda } \\
\text { menjadi mengetahui } \\
\text { rute menuji tempat } \\
\text { wisata Kelenteng } \\
\text { Sam Poo Kong di } \\
\text { Kota Semarang }\end{array}$ & 8 & 2 \\
\hline 8 & $\begin{array}{l}\text { Apakah anda } \\
\text { menjadi mengetahui } \\
\text { rute terpendek } \\
\text { menuju tempat } \\
\text { wisata Kelenteng } \\
\text { Sam Poo Kong di } \\
\text { Kota Semarang }\end{array}$ & 8 & 2 \\
\hline 9 & $\begin{array}{c}\text { Apakah anda } \\
\text { tertarik untuk } \\
\text { berkunjung ke Kota } \\
\text { Semarang }\end{array}$ & 10 & 0 \\
\hline
\end{tabular}

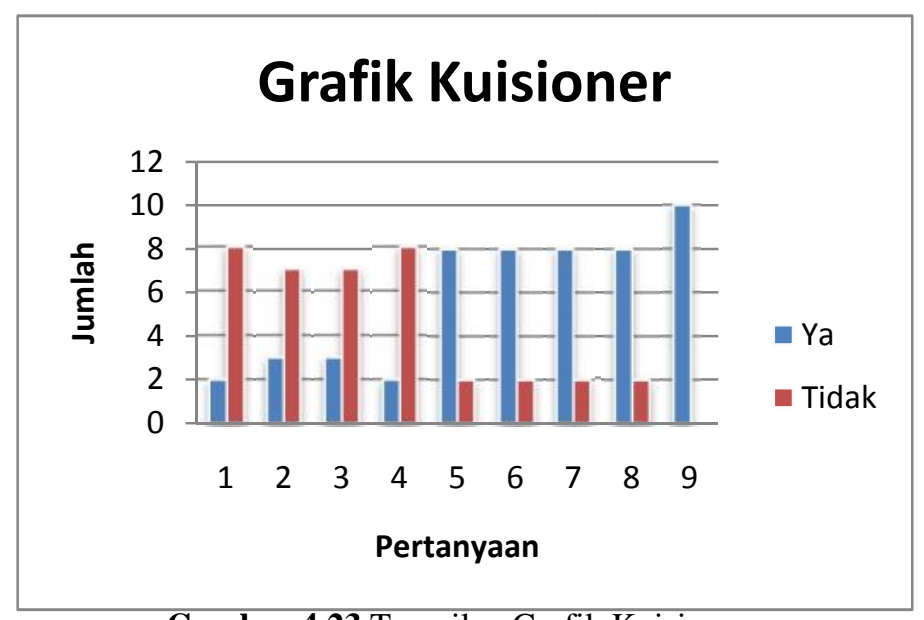

Gambar 4.23 Tampilan Grafik Kuisioner

\section{PENUTUP}

\subsection{Kesimpulan}

Dari hasil pengujian dan analisis aplikasi Sistem Informasi Geografis Pariwisata Kota Semarang berbasis Android maka dapat disimpulkan hal-hal sebagai berikut.

1. Google Map API dan Google Places API merupakan komponen utama dalam Sistem informasi Geografis daerah pariwisata kota Semarang

2. Global Positioning System berperan penting dalam menentukan keakuratan posisi dari pengguna

3. Sistem informasi geografis pariwisata kota Semarang bermanfaat untuk mengetahui lokasi wisata, tempat ibadah, ATM, Bandara di kota Semarang.

4. Sistem informasi geografis pariwisata kota Semarang berbasis Android dapat diakses oleh siapa saja tanpa perlu login.

5. Sistem informasi geografis pariwisata kota Semarang berbasis Android dapat digunakan dengan spesifikasi minimum sistem operasi Gingerbread.

\subsection{Saran}

Berdasarkan pengujian terhadap aplikasi Sistem Informasi Geografis Pariwisata Kota Semarang Berbasis Android yang telah dibuat, dapat diberikan beberapa saran sebagai berikut.

1. Sistem informasi geografis pariwisata kota Semarang ini dapat dikembangkan lebih lanjut dengan membuat sistem peringkat daerah wisata yang ingin dituju, sehingga dapat memberikan saran kepada wisatawan.

2. Penggunaan Eclipse dalam membuat Sistem Informasi Geografis berbasis android harus mempertimbangkan masalah sumberdaya perangkat bergerak, terutama pada ukuran layar. Sebab ada banyak model smartphone dengan berbagai ukuran layar. Jadi 
dalam mendesain harus menyesuaikan ukuran layar yang paling kecil.

3. Perlu dilakukan penelitian lebih lanjut mengenai bagaimana membuat agar Sistem Informasi Geografis dapat diterapkan lintas sistem operasi seperti Blackberry dan iOS dengan menggunakan Eclipse.

\section{DAFTAR PUSTAKA}

[1] Matthews, Robbie, Beginning Android Tablet Programming, Springer Science, New York, 2011.

[2] Mednieks Zigrud, Dormin Laird, G.Blake Meike, And Masumi Nakamura, Programming Android, O'Reilly Media Inc, United States of America, 2011.

[3] T, Sutton, O. Dassau, and M.Sutton, $A$ Gentle Introduction to GIS, Eastern Cape, South Africa, 2009.

[4] Gramlich, Nicolas, Android Programming, Andbook Anddev, 2007.

[5] Cinar, Onur, Android Apps with Eclipse, Apress Springer Science, New York, 2012.

[6] Svennerberg, Gabriel, Beginning Google Maps API 3, Apress Springer Science, New York, 2010.

[7] Allen, Grant, Beginning Android 4, Apress Springer Science, New York, 2012.

[8] Davis, Scott. GIS for Web Developers, The Pragmatic Bookshelf, Texas, 2007.
[9] Davis, Scott, Google Maps API V2, The Pragmatic Bookshelf, Texas, 2006.

[10] Crick, Will. Introduction to ArcGIS API for Android, Esri, Palm Springs

California, 2011.

[11] Kundyanirum, Ambrina, Sistem Informasi Geografis Pariwisata Kota Semarang, Skripsi S-1 Universitas Diponegoro, Semarang, 20013.

[12] Sulistianto, Widy, Aplikasi Mobile GIS Berbasis Android Lokasi Perguruan Tinggi Provinsi Daerah Istimewa Yogyakarta, Skripsi S-1 UPN Veteran, Yogyakarta, 2011.

[13] Nugroho, Bunafit, PHP dan MySQL dengan Editor Dreamweaver MX, Penerbit Andi, Yogyakarta, 2004.

[14] Kadir, Abdul, Pengenalan Sistem Informasi, Penerbit Andi, Yogyakarta, 2003.

[15] Chang, Kang Tsung, Introduction To Geographic Information System Second Edition, McGraw Hill, New York, 2004.

[16] Pilone,Dan dan Neil Pitman, UML2.0 in a Nutshell, O'Reilly Media Inc, United States Of America, 2005.

[17] Solichin, Achmad, Pemrograman Web dengan PHP dan MySQL, Jakarta, 2009.

[18] ---, http://www.php.net, Agustus 2013.

[19] ---,http://www.stackoverflow.org,

Agustus 2013.

[20] ---, http://wptrafficanalyzer.in, Agustus 2013. 


\section{BIODATA PENULIS}

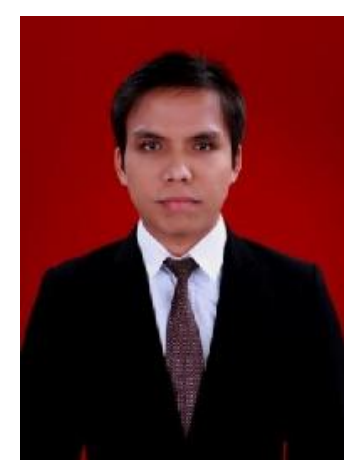

Richard R F S, lahir di

Pematangsiantar, $\quad 16$

Juni 1991. Memulai

pendidikan mulai dari

SD KalamKudus,

SMP Kalam Kudus,

SMA Kalam Kudus

Pematangsiantar. Dan

saat ini sedang

melanjutkan studi di

Jurusan Teknik Sistem

Komputer, Fakultas

Teknik, Universitas

Diponegoro .

Menyetujui,

Dosen Pembimbing I

\section{Ir.Kodrat Imam Satoto, M.T. \\ NIP 196310281993031002}

Dosen Pembimbing II

Kurniawan Teguh Martono, S.T.,M.T.

NIP 198303192010121002 